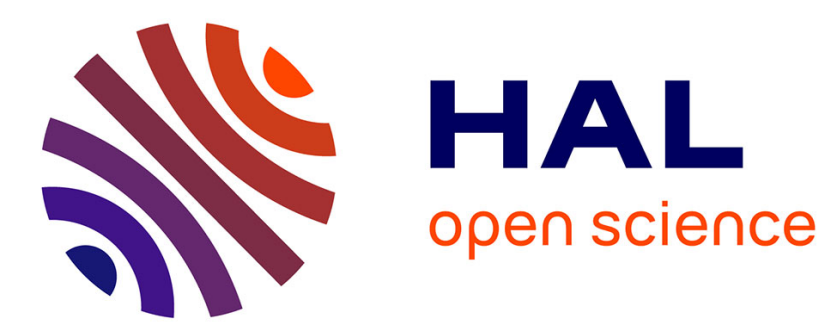

\title{
Texture effect of neodymium doped gallium oxide thin films on their optical properties
}

Céline Lecerf, Philippe Marie, Julien Cardin, François Jomard, Xavier Portier

\section{To cite this version:}

Céline Lecerf, Philippe Marie, Julien Cardin, François Jomard, Xavier Portier. Texture effect of neodymium doped gallium oxide thin films on their optical properties. Optical Materials, 2011, 33 (7), pp.1131-1134. 10.1016/j.optmat.2010.10.026 . hal-01147175

\section{HAL Id: hal-01147175 \\ https://hal.science/hal-01147175}

Submitted on 3 Apr 2017

HAL is a multi-disciplinary open access archive for the deposit and dissemination of scientific research documents, whether they are published or not. The documents may come from teaching and research institutions in France or abroad, or from public or private research centers.
L'archive ouverte pluridisciplinaire HAL, est destinée au dépôt et à la diffusion de documents scientifiques de niveau recherche, publiés ou non, émanant des établissements d'enseignement et de recherche français ou étrangers, des laboratoires publics ou privés. 


\title{
Texture effect of neodymium doped gallium oxide thin films on their optical properties
}

\author{
C. Lecerf ${ }^{\mathrm{a}, *}$, P. Marie ${ }^{\mathrm{a}}$, J. Cardin ${ }^{\mathrm{a}}$, F. Jomard ${ }^{\mathrm{b}}$, X. Portier ${ }^{\mathrm{a}}$ \\ ${ }^{a}$ CIMAP, CEA/UMR CNRS 6252/ENSICAEN/Université de Caen Basse Normandie, 6 Boulevard Maréchal Juin, 14050 CAEN, France \\ b GEMaC, UMR 8635/CNRS Université de Versailles-Saint-Quentin, 1, place A. Briand, 92195 Meudon Cedex, France
}

\begin{abstract}
A B S T R A C T
Neodymium doped $\beta-\mathrm{Ga}_{2} \mathrm{O}_{3}$ films were elaborated on ( $\left.\begin{array}{lll}1 & 0 & 0\end{array}\right)$ silicon and $\left(\begin{array}{llll}0 & 0 & 0 & 1\end{array}\right)$ sapphire substrates by the radiofrequency magnetron sputtering method. X-ray diffraction, transmission electron microscopy, spectroscopic ellipsometry and photoluminescence measurements were performed to characterize and compare layers elaborated on the two substrates. Also, the Nd content effects were investigated. Films prepared on sapphire substrates were found to form a close orientation relationship with the substrate $\left(\begin{array}{lll}-2 & 0 & 1\end{array}\right) \beta-\mathrm{Ga}_{2} \mathrm{O}_{3} \|\left(\begin{array}{llll}0 & 0 & 0 & 1\end{array}\right)$ sapphire, whatever the Nd content in the matrix. By contrast, the films grown on silicon substrates lose this texture for high $\mathrm{Nd}$ concentrations with a concomitant decrease of the $\mathrm{Nd}$ ions luminescence.
\end{abstract}

\section{Introduction}

For the past few years, many studies have paid much attention on Transparent Conductive Oxides (TCOs) due to their singular electrical and optical properties. Domains of applications for the TCOs are wide, they can be used in building for example as energy-efficient windows, as transparent electrodes for solar cells, flat panel displays, and for other various optoelectronics devices. In practical, TCO industry is dominated by few materials, and mainly by ITO, $\mathrm{SnO}_{2}$ and $\mathrm{ZnO}$ films [1-5]. There are different trends for developing of new TCOs. The first direction is to increase the electrical conductivity properties. Another is to enlarge the optical transparency in the deep ultraviolet (DUV) region [6-8]. The use of UV light is increasing in various domains, such as lithography or for DNA and proteins detection (because of their intense absorption in the DUV range) or as transparent electrode for UV optoelectronic devices [7-11]. From this point of view $\mathrm{Ga}_{2} \mathrm{O}_{3}$ is a unique material which exhibits both DUV transparency and suitable electrical conductivity [12].

Monoclinic gallium oxide $\left(\beta-\mathrm{Ga}_{2} \mathrm{O}_{3}\right)$ is a wide band gap material ( $\sim 4.9 \mathrm{eV}$ or $250 \mathrm{~nm}$ in wavelength) [13]. This makes it very suitable to detect or emit light at short wavelength where standard TCOs such as ITO are opaque $[14,15]$. $\beta-\mathrm{Ga}_{2} \mathrm{O}_{3}$ with an oxygen deficiency shows a semiconductor behavior [16]. Additionally, it presents excellent chemical properties and thermal stabilities with a

* Corresponding author. Address: CIMAP-ENSICAEN, 6 Boulevard Maréchal Juin, 14050 CAEN cedex 4, France. Tel.: +33 2314526 61; fax: +33 231452557

E-mail address: celine.lecerf@ensicaen.fr (C. Lecerf). melting point at $1800^{\circ} \mathrm{C}$, which also makes it a good candidate for high temperature stable gas sensors [17]. Furthermore, because of its large spectral range of transparency, gallium oxide is an excellent host for rare earth (RE) ions. Some studies focused on luminescent properties of RE (mainly europium and erbium) doped gallium oxide [14,18-20]. In order to achieve optoelectronic applications such as electroluminescent devices, there is a need for explanation and clarification of luminescent mechanisms of RE doped $\mathrm{Ga}_{2} \mathrm{O}_{3}$.

In previous papers $[21,22]$, we reported on growth of neodymium doped gallium oxide thin films on silicon substrates. Structural and optical characterizations were achieved. Films showed a columnar growth and a wide spectral range of transparency from ultraviolet to infrared light. Photoluminescence measurements revealed the neodymium efficiency in the $\mathrm{Ga}_{2} \mathrm{O}_{3}$ matrix. In addition, Podhorodecki et al. proposed recently mechanisms of emission in $\mathrm{Ga}_{2} \mathrm{O}_{3}: \mathrm{Nd}^{3+}[23]$.

However, despite a slight texture of the films grown on silicon, the crystalline quality of these films is far to be perfect. In order to improve the structure of the films, and its effect on their properties, deposits on sapphire substrates were tested. Studies from other groups revealed that the $\mathrm{Ga}_{2} \mathrm{O}_{3} / \mathrm{Al}_{2} \mathrm{O}_{3}$ interface exhibits a preferred growth orientation of the film. These investigations show that the undoped films crystallised in the $\beta-\mathrm{Ga}_{2} \mathrm{O}_{3}$ phase with a strong $(-201)$ texture $[12,24,25]$. Furthermore, tin doped films have the same structural properties but these ones change from a critical temperature above which the crystal structure was tentatively identified as $\varepsilon-\mathrm{Ga}_{2} \mathrm{O}_{3}$ [12]. Our present work deals with 
neodymium doped gallium oxide films elaborated on sapphire substrates. Their structural and optical properties are investigated and compared to the films elaborated on silicon substrates. The influence of the doping content is also discussed.

\section{Experimental}

Neodymium doped gallium oxide films were elaborated by radiofrequency magnetron sputtering of a $\mathrm{Ga}_{2} \mathrm{O}_{3}$ target topped by $\mathrm{Nd}_{2} \mathrm{O}_{3}$ calibrated pellets. $\mathrm{Nd}$ content was varied by the number of pellets placed on the sputtered target surface. The $\mathrm{Nd}_{2} \mathrm{O}_{3}$-to$\mathrm{Ga}_{2} \mathrm{O}_{3}$ surface ratio is called $r$. The growth was performed simultaneously on both (1 000$)$-silicon and ( $\left.\begin{array}{llll}0 & 0 & 0 & 1\end{array}\right)$-sapphire substrates. All post-annealing treatments were carried out at $1000^{\circ} \mathrm{C}$ during $1 \mathrm{~h}$ under a continuous flow of pure nitrogen. Secondary ion mass spectrometry (SIMS) analyses were performed with a CAMECA IMS $4 \mathrm{f}$ to determine the $\mathrm{Nd}$ concentrations in the films. Both structural and optical properties were investigated. X-ray measurements were carried out using a Philips XPERT diffractometer with $\mathrm{CuK}_{\alpha}$ $(\lambda=1.5418 \AA)$ as X-ray source. A JEOL 2010F Transmission Electron Microscope (TEM) allowed cross-sectional views of the films. To be performed, electron beam was generated with a Field Electron Gun source at $200 \mathrm{kV}$ and a CCD camera was used to acquire images. Spectroscopic ellipsometry (SE) measurements were made thanks to a Jobin-Yvon ellipsometer (UVISEL). The incidence angle of the light on the film surface was $66.2^{\circ}$ and data were collected between 1.5 and $4.5 \mathrm{eV}$. A dispersion law was used to model the dielectric function of $\mathrm{Ga}_{2} \mathrm{O}_{3}$ [21]. Room temperature photoluminescence (PL) measurements were made using a Coherent INNOVA 90C CW Argon laser operated at $514 \mathrm{~nm}$ and $20 \mathrm{~Hz}$ chopped as an excitation source. The photon flux was constant and about $1.6 \times 10^{19} \mathrm{ph} \mathrm{cm}^{-2} \mathrm{~s}^{-1}$. The $\mathrm{Nd}^{3+} \mathrm{PL}$ was measured thanks to a Jobin-Yvon monochromator and with a Northcoast Germanium detector cooled with liquid nitrogen. The PL signal was recorded on a personal computer via a SRS lock-in amplifier referenced to the chopper frequency.

\section{Results and discussion}

\subsection{Chemical analyses}

SIMS analyses were performed on as-grown films of about $1 \mu \mathrm{m}$ thick and elaborated on silicon substrates. The reference used is the highly doped sample, for which the neodymium content was measured by Rutherford Backscattering Spectroscopy.

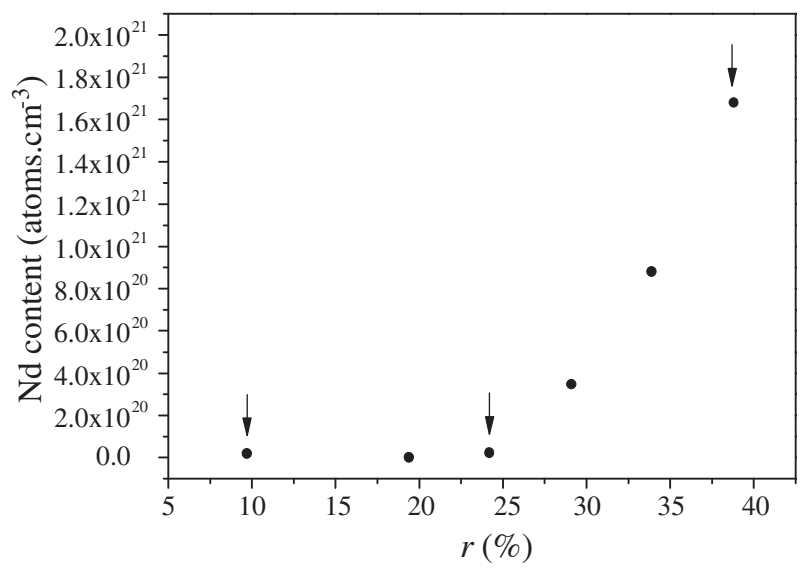

Fig. 1. Plot of the neodymium content as a function of $r$.
Fig. 1 is a plot of the Nd content incorporated in as-grown films elaborated for different $r$ values. As expected, an increase of the $\mathrm{Nd}$ content is observed but its evolution is nonlinear. Below $r=24.2 \%$, the Nd concentration is almost constant. Above $24.2 \%$, the doping quantity in the films increases exponentially with $r$ to reach a maximum value for $r=38.8 \%$. Note that these data do not give a precise indication of the Nd distribution in the film after annealing.

In this work, we focused our attention on three different $r$ values pointed by arrows in Fig. 1 i.e. 9.7\%, 24.2\% and 38.8\%. These $r$ values correspond to $2 \times 10^{19}, 2.4 \times 10^{19}$, and $1.7 \times 10^{21}$ at. $\mathrm{cm}^{-3}$, respectively. In the next sections, all the data were obtained from annealed samples.

\subsection{XRD investigations}

$\theta-2 \theta$ scans were recorded for samples elaborated on both silicon and sapphire substrates and for different $r$ values. These data

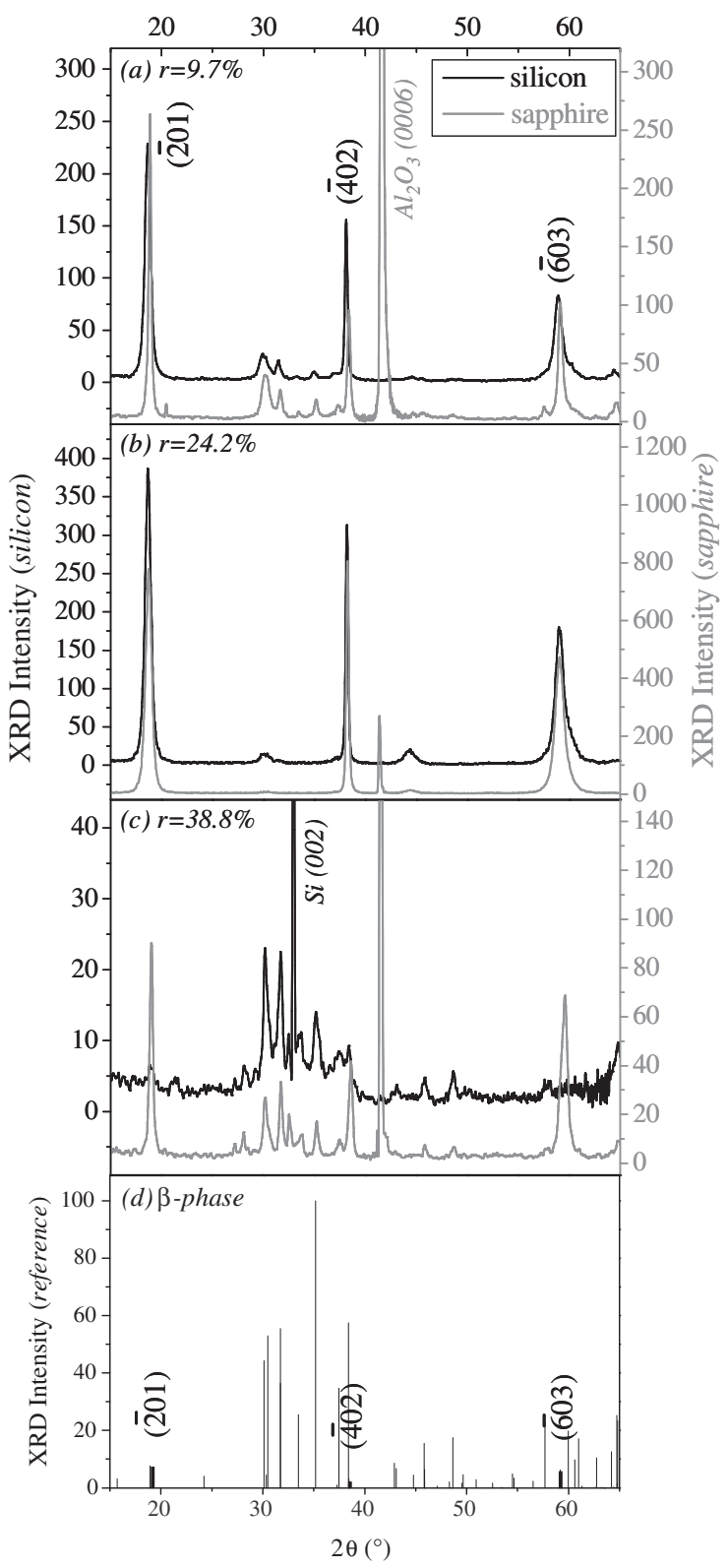

Fig. 2. XRD patterns of films deposited on silicon and sapphire substrates for $r=9.7 \%$ (a), $24.2 \%$ (b) and $38.8 \%$ (c). The diffraction pattern of the monoclinic $\beta$ $\mathrm{Ga}_{2} \mathrm{O}_{3}$ phase is presented in (d). 
are reported in Fig. 2(a)-(c), corresponding to 9.7\%, 24.2\% and $38.8 \%$, respectively. For films grown on sapphire, note the ( 0006 ) peak from the substrate at $2 \theta=41.69^{\circ}$. Apart from this peak, all the other peaks are coming from the film. For all $r$ values, the diffraction peaks positions are consistent with the structure of the monoclinic $\beta$-phase of $\mathrm{Ga}_{2} \mathrm{O}_{3}$ whose theoretical diffraction pattern has been reported in Fig. 2(d). Whatever the $r$ value, the patterns show a growth texture of the films governed by the $(-201)$ planes. Regarding the related diffraction peak intensities, this $(-201)$ texture appears slightly more pronounced for $r=24.2 \%$.

In the case of the $\left(\begin{array}{lll}1 & 0 & 0\end{array}\right)$-oriented silicon substrate, films present also this ( -201 ) preferred orientation, but this latter diminishes gradually with increasing $r$. For $r=38.8 \%$, the texture effect has completely disappeared whereas it remains well visible for the film grown on sapphire despite a lower intensity of the ( -201 ) peak compared to that observed for $r=24.2 \%$.

\subsection{TEM observations}

Fig. 3 shows dark field TEM images (cross-sectional views) of Nd-doped gallium oxide films grown on sapphire with $r=24.2 \%$ (Fig. 3(a)) and on silicon with $r=38.8 \%$ (Fig. 3(b)). The images have been obtained by selecting the $(-201)$ spot or ring of $\beta-\mathrm{Ga}_{2} \mathrm{O}_{3}$ in the diffraction pattern.

In Fig. 3(a), the presence of large bright regions with columnar shapes is consistent with the $(-201)$ texture. The average column width is about $95 \mathrm{~nm}$. The observation (not shown) of the film on silicon during the same run $(r=24.2 \%)$, leads to a similar configuration but the texture is less obvious and the column width is only $55 \mathrm{~nm}$. For $r=38.8 \%$, the film grown on silicon has completely lost the above mentioned texture confirming the XRD data. The film is constituted of nanograins of $\beta-\mathrm{Ga}_{2} \mathrm{O}_{3}$, whose average size is about $10 \mathrm{~nm}$. It is also important to note that some voids are observed in the film.
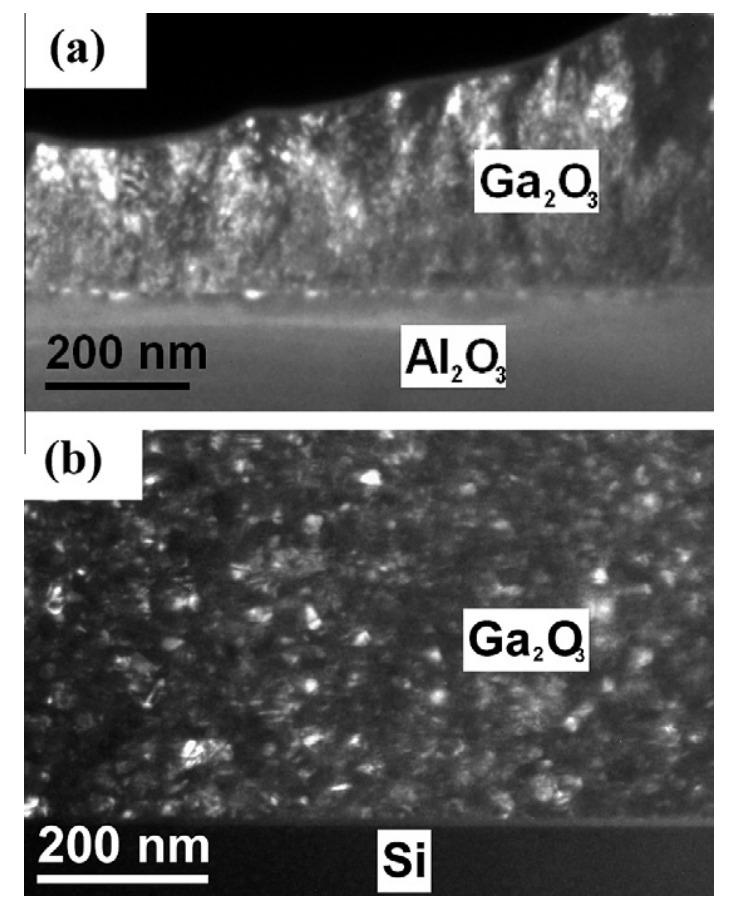

Fig. 3. Dark field TEM images of gallium oxide films grown on sapphire (a) and silicon (b). The former case shows a well textured film whereas the latter film is composed by nanograins.

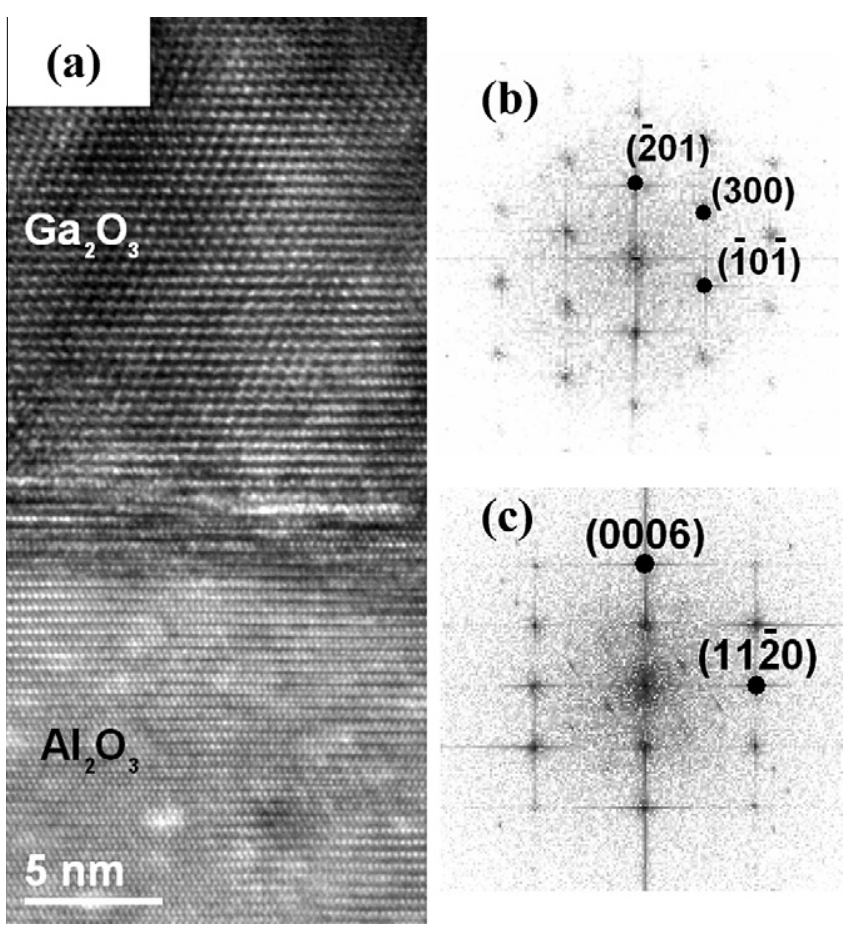

Fig. 4. (a) HREM image of the interface between the $\beta-\mathrm{Ga}_{2} \mathrm{O}_{3}$ and sapphire along the $\left[\begin{array}{llll}-1 & 1 & 0 & 0\end{array}\right]$ direction of the substrate; (b) FFT of a region of the film and (c) FFT of a region of the substrate.

Fig. 4 is an HREM image of the film grown on sapphire for $r=24.2 \%$. It clearly shows the almost perfect match between the two structures. The $(-201)$ planes ( $d$ spacing: $0.468 \mathrm{~nm}$ ) of

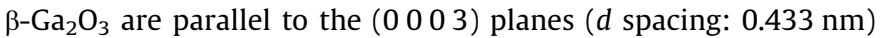
of sapphire. For the observed column, the orientation relationship is $\left(\begin{array}{lll}-2 & 0 & 1\end{array}\right) \beta-\mathrm{Ga}_{2} \mathrm{O}_{3} \|\left(\begin{array}{llll}0 & 0 & 0 & 1\end{array}\right) \mathrm{Al}_{2} \mathrm{O}_{3}$ and $\left[\begin{array}{lll}0 & 1 & 0\end{array}\right] \beta-\mathrm{Ga}_{2} \mathrm{O}_{3} \|\left[\begin{array}{llll}-1 & 1 & 0 & 0\end{array}\right]$ $\mathrm{Al}_{2} \mathrm{O}_{3}$.

\subsection{Spectroscopic ellipsometry results}

The real refractive index $n$ and the absorption coefficient $\alpha$ versus energy have been extracted from the ES calculations and are reported in Fig. 5 for the two extreme $r$ values (9.7\% and 38.8\%).

Their evolution as a function of $r$ has been studied. For $r=9.7 \%$, $n$ increases from 1.82 (at $1.5 \mathrm{eV}$ ) to 2.16 (at $4.5 \mathrm{eV}$ ). For $r=38.8 \%, n$

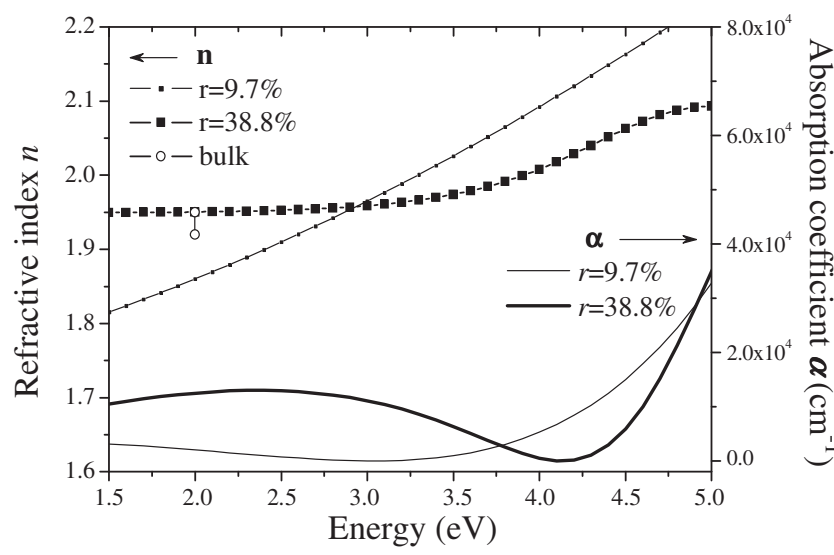

Fig. 5. Refractive indexes and absorption coefficients for films grown on sapphire with $r=9.7 \%$ and $38.8 \%$. Refractive index of bulk material at $2 \mathrm{eV}$ is included for comparison (see Ref. [26]). 


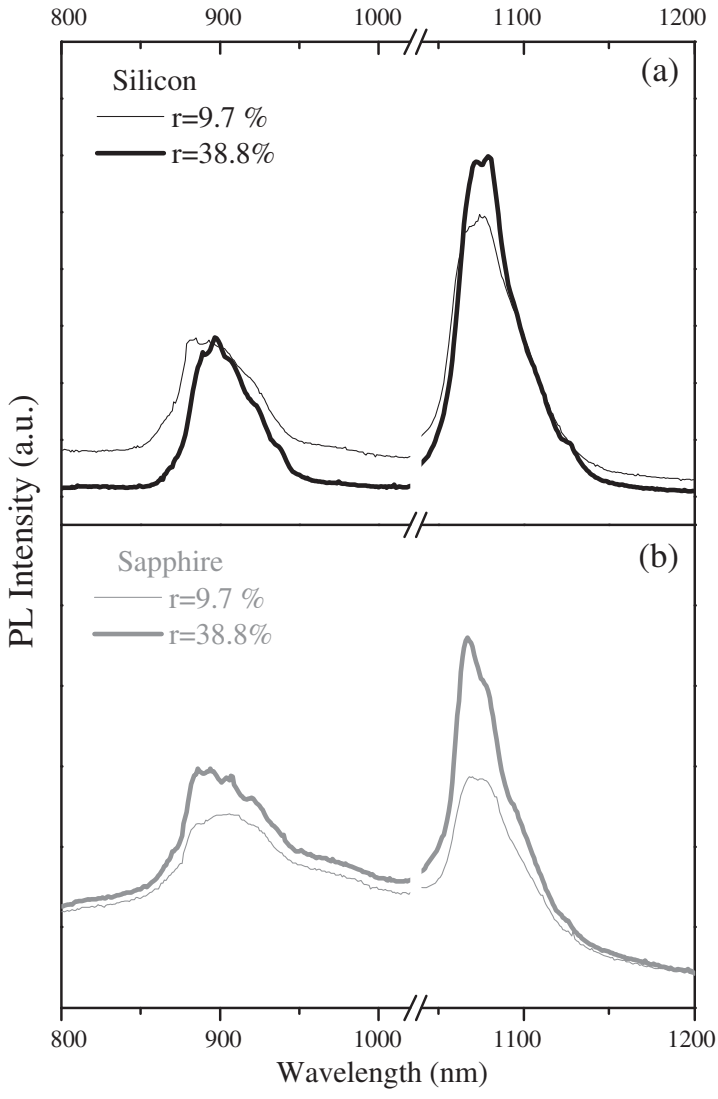

Fig. 6. PL spectra of films grown on silicon (a) and sapphire (b) substrates.

equals to 1.95 (at $1.5 \mathrm{eV}$ ) and it increases slowly up to 2.06 (at $4.5 \mathrm{eV}$ ). The $n$ dispersion values are consistent with the expected ones, compared to films prepared by electron-beam and spray pyrolysis (1.70-2.25 in the considered spectral range [27]) and it can be noted that $n$ increases more and more slowly when $r$ rises.

The absorption coefficients are also typical to those of $\mathrm{Ga}_{2} \mathrm{O}_{3}$ bulk material and usually obtained for TCO materials. For $r=9.7 \%$ and from 1.5 to $4 \mathrm{eV}, \alpha$ is lower than $3 \times 10^{3} \mathrm{~cm}^{-1}$. For higher $r$ values and in the same spectral range, $\alpha$ is increasing but it remains lower than $1.4 \times 10^{4} \mathrm{~cm}^{-1}$. Above $4.2 \mathrm{eV}$, the transparency decreases in both cases.

The optical properties of films prepared on silicon wafers were already reported and the same singular properties of $\mathrm{Ga}_{2} \mathrm{O}_{3}$ are observed [22].

\subsection{Photoluminescence results}

PL activity of the $\mathrm{Ga}_{2} \mathrm{O}_{3}: \mathrm{Nd}^{3+}$ films grown on silicon and sapphire substrates are illustrated in Fig. 6(a) and (b), respectively. Measurements have been performed for the two extreme $r$ values (9.7\% and 38.8\%). The emission bands correspond to ${ }^{4} \mathrm{~F}_{3 / 2} \rightarrow{ }^{4} \mathrm{I}_{9 / 2}$ (around $900 \mathrm{~nm}$ ) and ${ }^{4} \mathrm{~F}_{3 / 2} \rightarrow{ }^{4} \mathrm{I}_{9 / 2}$ (around $1075 \mathrm{~nm}$ ) transitions of $\mathrm{Nd}^{3+}$. Both silicon and sapphire substrates allow the PL activity of the rare earth ions to be observed.

Surprisingly, the evolution of the PL activity for a given Nd concentration in the matrix depends on the substrate nature. From the lowest to the highest Nd content, in the silicon case, the PL intensity for the ${ }^{4} \mathrm{~F}_{3 / 2} \rightarrow{ }^{4} \mathrm{I}_{9 / 2}$ transition (1075 nm) increases by a factor of 1.2 whereas in the sapphire case, this factor is 1.8 . This can be explained by the related structural data. Indeed, according to the XRD patterns and the TEM observations, this difference in the PL response is accompanied by the loss of the $(-201)$ texture of the $\mathrm{Ga}_{2} \mathrm{O}_{3}$ film and the formation of nanocrystallites randomly oriented. In addition, in the case of the film deposited on sapphire with the higher $\mathrm{Nd}$ content, the hyperfine transitions related to the ${ }^{4} \mathrm{~F}_{3 / 2} \rightarrow{ }^{4} \mathrm{I}_{9 / 2}$ band start to be visible which is typical of an improvement of the $\mathrm{Nd}^{3+}$ environment i.e. a better matrix with less defects. A possible mechanism involved giving rise to the $\mathrm{Nd}$ luminescence is described elsewhere in details by Podhorodecki et al. [23].

\section{Conclusion}

$\mathrm{Ga}_{2} \mathrm{O}_{3}: \mathrm{Nd}^{3+}$ films with different Nd concentrations were grown on silicon and on sapphire substrates. A clear degradation of the $(-201)$ texture with $\mathrm{Nd}$ content is observed with a silicon substrate whereas a film grown on a sapphire substrate remains highly textured even for high Nd concentrations. The PL signal of the Nd ions is affected by the loss of the film texture. The presence of voids in the films grown on silicon could explain this feature. The arising question is whether this result is due to a different $\mathrm{Nd}$ distribution in the matrix and/or to an intrinsic factor linked to the matrix (less defects, stress release,....). Complementary PL measurements are in progress to find out the fundamental relationship between the optical properties and the microstructure of the film. Moreover, in a near future, a similar study will be carried out with gallium oxide doped with europium.

\section{References}

[1] B.G. Lewis, D.C. Paine, MRS Bull. 25 (2000) 22-25.

[2] T. Minami, MRS Bull. 25 (2000) 38-44

[3] T. Minami, Semicond. Sci. Technol. 20 (2005) S35-S44.

[4] D.S. Ginley, C. Bright, MRS Bull. 25 (2000) 15-18.

[5] R.G. Gordon, MRS Bull. 25 (2000) 52-57.

[6] K. Ellmer, R. Mientus, Thin Solid Films 516 (2008) 4620-4627.

[7] H. Hosono, H. Ohta, M. Orita, K. Ueda, M. Hirano, Vacuum 66 (2002) 419-425.

[8] H. Ohta, K. Nomura, H. Hiramatsu, K. Ueda, T. Kamiya, M. Hirano, H. Hosono, Solid-State Electron. 47 (2003) 2261-2267.

[9] H. Hosono, Thin Solid Films 515 (2007) 6000-6014.

[10] T. Kamiya, H. Hiramatsu, K. Nomura, H. Hosono, J. Electroceramics 17 (2006) 267-275.

[11] M. Orita, H. Ohta, M. Hirano, H. Hosono, Appl. Phys. Lett. 77 (2000) 4166-4168

[12] M. Orita, H. Hiramatsu, H. Ohta, M. Hirano, H. Hosono, Thin Solid Films 411 (2002) 134-139.

[13] S. Geller, J. Chem. Phys. 33 (1960) 676-684.

[14] T. Miyata, T. Nakatani, T. Minami, J. Lumin. 87-89 (2000) 1183-1185.

[15] M.L. Pang, W.Y. Shen, J. Lin, J. Appl. Phys. 97 (2005) 033511.

[16] L. Binet, D. Gourier, J. Phys, Chem. Solids 59 (1998) 1241-1249.

[17] M. Ogita, N. Saika, Y. Nakanishi, Y. Hatanaka, Appl. Surf. Sci. 142 (1999) $188-191$.

[18] T. Biljan, A. Gajovic, Z. Meic, J. Lumin. 128 (2008) 377-382.

[19] E. Nogales, J.A. García, B. Méndez, J. Piqueras, K. Lorenz, E. Alves, J. Phys. D: Appl. Phys. 41 (2008) 065406.

[20] P. Gollakota, A. Dhawan, P. Wellenius, L.M. Lunardi, J.F. Muth, Y.N. Saripalli, H.Y. Peng, H.O. Everitt, Appl. Phys. Lett. 88 (2006) 221906

[21] P. Marie, X. Portier, J. Cardin, Phys. Stat. Sol. (a) 205 (2008) 1943-1946.

[22] C. Lecerf, P. Marie, C. Frilay, J. Cardin, X. Portier, Rare earth doping of advanced materials for photonic applications book series, Mater. Res. Soc. Symp. Proc. 1111 (2009) 259.

[23] A. Podhorodecki, M. Banski, J. Misiewicz, C. Lecerf, P. Marie, J. Cardin, X. Portier J. Appl. Phys. 108 (2010) 63535.

[24] Y. Kokubun, K. Miura, F. Endo, S. Nakagomi, Appl. Phys. Lett. 90 (2007) 031912

[25] V. Gottschalch, K. Mergenthaler, G. Wagner, J. Bauer, H. Paetzelt, C. Sturm, U. Teschner, Phys. Stat. Sol. (a) 206 (2009) 243-249.

[26] CRC Handbook of Chemistry and Physics, 70th ed., R.C. Weast (Ed.), CRC, Boca Raton, 1989, p. B-92.

[27] M.F. Al-Kuhaili, S.M.A. Durrani, E.E. Khawaja, Appl. Phys. Lett. 83 (2003) 4533. 